\title{
Optical and electronic properties of $\mathrm{Cu}-\mathrm{Mn}$ solid solutions
}

\author{
V.M. Bondar ${ }^{1}$, V.S. Stashchuk ${ }^{1}$, O.P. Polianska ${ }^{1}$, Ie.O. Chernukha ${ }^{1}$, B.A. Tsuk ${ }^{1}$, V.O. Lysiuk ${ }^{2}$ \\ ${ }^{I}$ Taras Shevchenko Kyiv National University, Physics Department, \\ 64,Volodymyrska str.,01601 Kyiv,Ukraine; e-mail: bond270587@i.ua \\ ${ }^{2}$ V. Lashkaryov Institute of Semiconductor Physics, NAS of Ukraine, 03028 Kyiv, Ukraine
}

\begin{abstract}
The optical properties of $\mathrm{Cu}-\mathrm{Mn}$ alloys with $\mathrm{Mn}$ concentrations of 2, 5, 10 and $17.5 \%$ (which corresponds to the $\gamma$-solid solutions) were studied within a wide spectral range of 0.23 to $2.8 \mu \mathrm{m}(0.44 \ldots 5.39 \mathrm{eV})$. Real and imaginary parts of the refractive index were measured, other optical properties such as dielectric constant, optical conductivity and the coefficient of specular reflectance at normal incidence were calculated being based on them. The analysis of the dispersion dependences $\varepsilon(h v), R(h v)$ and $\sigma(h v)$ enabled us to offer the electronic structure model for these alloys. According to this model, the electronic spectra (dependence of the density of electronic states on energy $N(E)$ ) of alloys with the indicated concentrations of components are the superposition of electronic spectra of $\mathrm{Cu}$ host, with weights equal to $\mathrm{Cu}$ concentrations, and the density of states within the impurity band, calculated using the experimental data.
\end{abstract}

Keywords: $\mathrm{Cu}-\mathrm{Mn}$ alloy, electronic structure, impurity band, collision rate, density of electronic states, optical conductivity spectrum.

Manuscript received 19.12.12; revised version received 28.02.13; accepted for publication 19.03.13; published online 25.06.13.

\section{Introduction}

$\mathrm{Cu}-\mathrm{Mn}$ alloys, unlike $\mathrm{Cu}-\mathrm{Ni}$ alloys, which are singlephase [1] in a wide range of concentrations, form twophase solid solutions with $\gamma$-phase $\mathrm{Cu}$ and $\varepsilon$-phase $\mathrm{Mn}$. At the same time, other transition metals such as $\mathrm{Fe}, \mathrm{Co}$ or $\mathrm{Cr}$ are almost insoluble in $\mathrm{Cu}$ [2]. On the other hand, it is well known that the impurities of 3d-transition metals form localized magnetic moments [3], which gave impetus to theoretical studies of electronic properties of the compounds with 3d-transition metals [4]. It was found that with the addition of $3 d$-transition metals to copper, new impurity bands are formed in the electronic spectrum of the solvent. They are located below the Fermi level $E_{\mathrm{F}}$ [5]. This enabled to determine the parameters that characterize the impurity band, as in the case of alloys $\mathrm{Cu}-\mathrm{Fe}$ [6], $\mathrm{Cu}-\mathrm{Co}$ [7] and $\mathrm{Cu}-\mathrm{Cr}$ [8]. However, so far, to our knowledge, the optical properties of alloys of copper with another 3d-transition metal antiferromagnetic $\mathrm{Mn}$ - were not studied. Therefore, in this work we study the optical properties and, being based on them, the electronic structure of $\mathrm{Cu}-\mathrm{Mn}$ compounds rich in $\mathrm{Cu}$.

\section{Experimental procedure}

Optical properties of solid solutions of $\mathrm{Cu}-\mathrm{Mn}$ with $\mathrm{Mn}$ concentrations of 2, 5, 10 and $17.5 \%$, and pure $\mathrm{Cu}$ and Mn were investigated within the spectral range $\lambda=$ $0.23 \ldots 2.8 \mu \mathrm{m} \quad(h v=0.44 \ldots 5.39 \mathrm{eV})$ by Beattie ellipsometric method using an original spectral ellipsometer [9]. The ellipsometer included the following functional units: block of light sources, consisting of deuterium-mercury lamp ART-250, hydrogen lamp ICE-25 and halogen lamp КГМ-150; block of radiation detectors, which included photoelectron multipliers PEM-39A and PEM-62; G-5 goniometer, which housed the Glan prism polarizer and analyzer. The studied samples were located on the goniometer sample stage. The setup also included the electrical components for amplifying electrical signals and their registration by standard digital voltmeters and PC. Ellipsometric parameters $\Delta$ (phase shift between pand s-polarization components) and $\psi$ (azimuth of the restored linear polarization) were measured within this setup in the specified spectral range at a fixed angle of incidence close to the principal one. Based on $\Delta$ and $\psi$ 
the refraction and absorption indices $n$ and $\chi$ were calculated, and then the dielectric constant $\varepsilon=n^{2}-\chi^{2}$, optical conductivity $\sigma=4 \pi \varepsilon_{0} n \chi \nu$ ( $v-$ light frequency) and the reflection coefficient at normal incidence $R=\frac{(n-1)^{2}+\chi^{2}}{(n+1)^{2}+\chi^{2}}$ were obtained.

$\mathrm{Cu}-\mathrm{Mn}$ alloy samples were obtained by vacuum-arc melting of pure $\mathrm{Cu}$ and $\mathrm{Mn}$ with corresponding weights in argon atmosphere by repeated melting. To achieve greater uniformity samples were annealed in the same atmosphere at $900{ }^{\circ} \mathrm{C}$ for $24 \mathrm{~h}$. Sample mirror surfaces were prepared by mechanical grinding and polishing with diamond paste with subsequent recrystallization annealing and electropolishing. X-ray structure and phase analysis of alloy samples was also performed with ДРОН-3.0 X-ray diffractometer.

\section{Results and discussion}

Analysis of optical properties' dependence on the photon energy $h v$ in the investigated spectral range $h v=0.44 \ldots 5.39 \mathrm{eV}$ provides information about changes in the electronic structure of $\mathrm{Cu}$ with the addition of Mn. First, we consider the dispersion curves of reflection coefficient $R(h v)$ of studied $\mathrm{Cu}-\mathrm{Mn}$ alloys and pure $\mathrm{Cu}$ and $\mathrm{Mn}$, shown in Fig. 1. The figure shows that the reflection curve $R(h v)$ for pure $\mathrm{Cu}$ is a smooth curve without any anomalies, although the value of $R$ varies within wide limits $(35 \ldots 99 \%)$, except for the shallow minimum located at about $4.2 \mathrm{eV}$, caused by electron interband transitions. At the same time, the value of $R$ of $\mathrm{Mn}$ is much lower than that for $\mathrm{Cu}$, especially in the ultraviolet region, where the values of $R$ differ by almost 3.5 times. A broad maximum is observed in the infrared region $(h v<1.1 \mathrm{eV})$ for $\mathrm{Mn}$, located at about $0.95 \mathrm{eV}$. It is seen that in this area $R$ value for $\mathrm{Cu}$ depends weakly on energy, indicating the dominance of interband electron transitions. With addition of $\mathrm{Mn}$, the $R$ value in the ultraviolet spectral region $(h v>3.0 \mathrm{eV})$ decreases with increasing the $\mathrm{Mn}$ concentration, and the minimum at $4.2 \mathrm{eV}$ characteristic for pure $\mathrm{Cu}$ does not appear in $R(h v)$ curves of alloys with Mn concentrations higher than $10 \%$. The behavior of the curve $R(h v)$ for $\mathrm{Cu}-$ $17.5 \% \mathrm{Mn}$ alloy is quite peculiar, as a maximum at $3.85 \mathrm{eV}$ clearly appears in the curve, which is virtually absent in other alloys. It is speculated that with further increase in the manganese concentration this maximum intensity will increase, as it is observed in the $R(h v)$ curve of pure manganese. Therefore, the most significant changes in the $R(h v)$ spectra of alloys are observed in the infrared region (with $h v<1.5 \mathrm{eV}$ ), which indicates the increasing role of interband transitions with the increase of manganese concentrations.

In what follows, we proceed to analyze the dispersion of the dielectric constant $\varepsilon(h v)$, shown in Fig. 2. The figure shows that the $\varepsilon(h v)$ curves for alloys with a low Mn content are similar to the pure copper $\varepsilon(h v)$ curve, which decreases monotonically with the decrease in energy, which is typical for normal dispersion. In the samples with high Mn concentrations, as well as for pure $\mathrm{Mn}$, the anomalous dispersion is observed in $\varepsilon(h v)$ curves at $1.0 \ldots 3.0 \mathrm{eV}$, which indicates the dominance of interband electron transitions within this spectral range. Additional information can be obtained by analyzing the $\varepsilon(h v)$ curves at $(h v)=3.3 \ldots 4.5 \mathrm{eV}$, where the value of $\varepsilon$ for all studied alloys is close to zero, which is a necessary condition for the excitation of plasma oscillations.

Let us make a more detailed look at the dispersion of optical conductivity $\sigma(h v)$, which is proportional to the interband density of electronic states $G(h v)$ [10]. Experimental $\varepsilon(h v)$ curves of the investigated alloys and pure $\mathrm{Cu}$ and $\mathrm{Mn}$ are shown in Fig. 3. The features of $\sigma(h v)$ spectra of pure $\mathrm{Cu}$ and $\mathrm{Mn}$ are significantly different. At the energies $(h v)<1.5 \mathrm{eV}$, the optical conductivity value for $\mathrm{Cu}$ increases monotonically with the decrease in the energy $h v$, which indicates the dominance of intraband transitions that occur within each of the bands that cross the Fermi level $E_{\mathrm{F}}$. Characteristic features of $\varepsilon(h v)$ spectrum of $\mathrm{Cu}$ are the sharp interband absorption edge at $h v=2.1 \ldots 2.3 \mathrm{eV}$, centered at $2.2 \mathrm{eV}$, and an intense absorption band with a maximum near $4.72 \mathrm{eV}$, as well as minor spectrum features at $3.5 \ldots 4.4 \mathrm{eV} . \sigma(h v)$ curve of $\mathrm{Mn}$ is in turn characterized by a wide maximum at $2.2 \mathrm{eV}$ and a slight increase in $\sigma$ value in the IR range $(h v<0.5 \mathrm{eV})$ caused by intraband electron transitions. We analyze further the dispersion of optical conductivity $\sigma(h v)$ of $\mathrm{Cu}-\mathrm{Mn}$ alloys with the increase in the $\mathrm{Mn}$ concentration (Fig. 3).

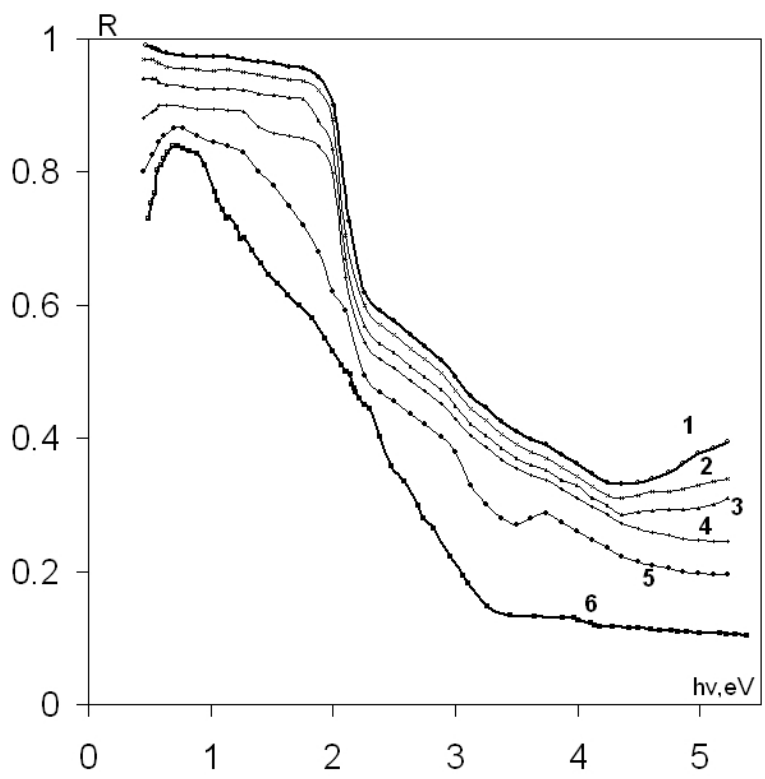

Fig. 1. Dispersion curves of reflectance $R(h v)$ for $\mathrm{Cu}(1)$, $\mathrm{Mn}(6)$ and their alloys containing 2(2), 5(3), $10(4)$ and $17.5 \% \mathrm{Mn}(5)$. 


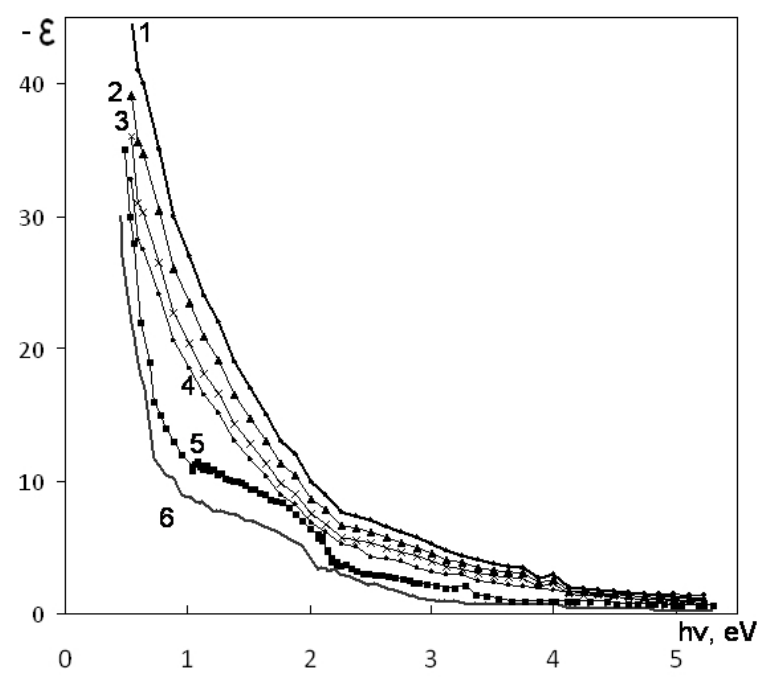

Fig. 2. Dispersion curves of the dielectric permittivity $\varepsilon(h v)$ for pure $\mathrm{Cu}(1)$ and $\mathrm{Mn}(6)$, and $\mathrm{Cu}-\mathrm{Mn}$ alloys containing $2(2)$, $5(3), 10(4)$ and $17.5 \% \mathrm{Mn}(5)$.

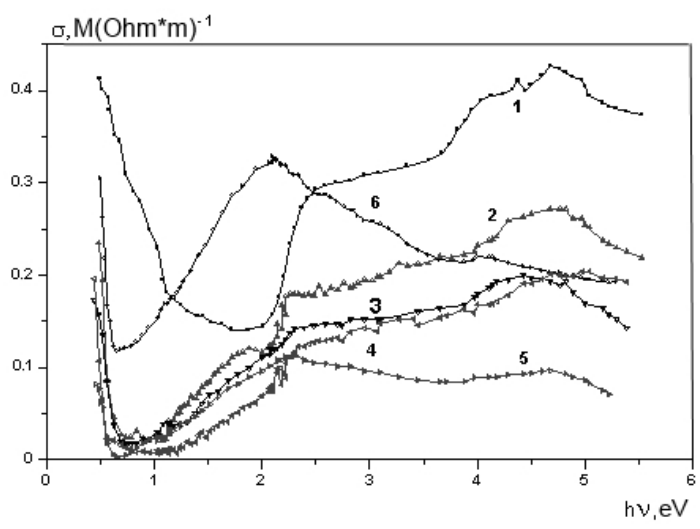

Fig. 3. Dispersion curves of interband optical conductivity $\sigma(h v)$ for pure $\mathrm{Cu}(1)$ and $\mathrm{Mn}(2)$ and $\mathrm{Cu}-\mathrm{Mn}$ alloys containing $2(3), 5(4), 10(5)$ and $17.5 \% \operatorname{Mn}(6)$. Curves (1) and (2) for the pure component raised by $0.1 \mathrm{M}(\mathrm{Ohm} \cdot \mathrm{m})^{-1}$.

Fig. 3 shows that the addition of low quantities of manganese to copper does not introduce significant changes in the overall shape of the absorption spectrum of copper. Characteristic features of the $\sigma(h v)$ spectrum of pure copper, in particular a short peak at $4.72 \mathrm{eV}$ and a sharp edge at $2.1 \ldots 2.3 \mathrm{eV}$, to some extent, appear in all the investigated $\mathrm{Cu}-\mathrm{Mn}$ alloys, as in $\mathrm{Cu}-\mathrm{Co}$ alloys [7]. It is found that the peak at $4.72 \mathrm{eV}$ is observed in all the alloys, hardly shifting along the energy scale. The sharp absorption edge at $2.2 \mathrm{eV}$ appears only in samples with the concentration of manganese below $10 \%$. At the same time, in the infrared spectral range $h v=$ $0.8 \ldots 1.8 \mathrm{eV}$ it is found that with addition of only $2 \% \mathrm{Mn}$ to $\mathrm{Cu}$ the contribution of "free" electrons in the overall absorption decreases sharply. At high concentrations of $\mathrm{Mn}$, this spectral area completely dominates due to interband electron transitions. This is due to the sharp increase of relaxation frequency of electrons in alloys as compared to pure components. It is found that addition of $\mathrm{Mn}$ to $\mathrm{Cu}$ at $\mathrm{Mn}$ concentrations higher than $5 \%$ gives a very strong effect - the appearance of an intense absorption band in the $\sigma(h v)$ curves in the near-IR range with a peak at $h v=1.9 \ldots 2.0 \mathrm{eV}$. Fig. 3 shows that a minimum is observed in the $\mathrm{Cu} \sigma(h v)$ curve in this region, while the maximum of absorption of pure $\mathrm{Mn}$, according to our experimental data, is located at $2.2 \mathrm{eV}$. Consequently, this band is not associated with pure $\mathrm{Cu}$ and $\mathrm{Mn}$, and is most likely associated with the resonant states arising in the electronic spectrum of $\mathrm{Cu}$ by addition of $\mathrm{Mn}$. The maximum, which is located at $2.5 \mathrm{eV}$ for the $\mathrm{Cu}-2 \% \mathrm{Mn}$ alloy, shifts in high-energy region of the spectrum, for example, for the $\mathrm{Cu}$ $17.5 \% \mathrm{Mn}$ alloy it is located at $2.15 \mathrm{eV}$ (see Fig. 3). Clearly, the formation of an additional band in alloys is due to changes in the electronic spectra of $\mathrm{Cu}-\mathrm{Mn}$ alloys. These changes are associated with the restructuring the energy spectrum of $\mathrm{Cu}$ and the appearance, as noted above, of resonant impurity states [10].

Further, we analyze the dispersion curves of the residual optical conductivity $\sigma(h v)$, which represents the difference between the experimental values $\sigma(h v)$ for alloys and the values of the optical conductivity of pure copper $\sigma_{\mathrm{Cu}}(h v)$ and pure manganese $\sigma_{\mathrm{Mn}}(h v)$ with respective weights $\quad \Delta \sigma(h v)=$ $\sigma(h v)-(1-c) \sigma_{\mathrm{Cu}}(h v)+c \sigma_{\mathrm{Mn}}(h v) \quad(c \quad$ is the $\mathrm{Mn}$ concentration), which for $\mathrm{Cu}-\mathrm{Mn}$ alloys containing 2, 5, 10, and $17.5 \%$ are shown in Fig. 4.

It is seen that for all the investigated alloys a new absorption band with a maximum at $2.05 \ldots 2.15 \mathrm{eV}$ appears. From the obtained data presented in Figs 3 and 4, the following conclusions can be made: first, at low concentrations of $\mathrm{Mn}(5 \%)$ it solves almost completely

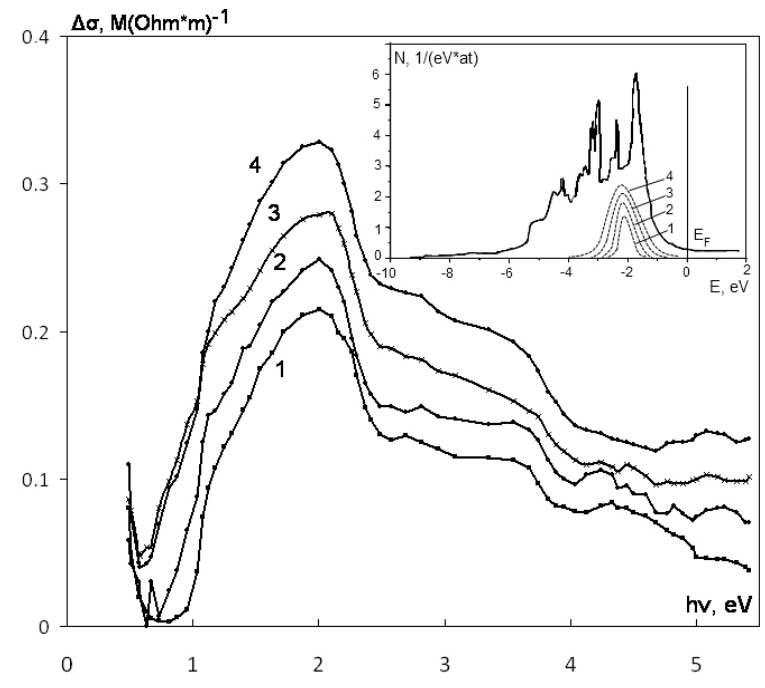

Fig. 4. Dispersion of residual optical conductivity $\Delta \sigma(h v)$ for $\mathrm{Cu}-\mathrm{Mn}$ alloys containing $2(1), 5(2), 10(3)$ and $17.5 \%$ $\mathrm{Mn}(4)$. All the curves are shifted upwards by $0.1 \mathrm{M}(\mathrm{Ohm} \cdot \mathrm{m})^{-1}$. Inset shows the density of states $N(E)$ curves for $\mathrm{Cu}$ [11] and $\mathrm{Cu}-\mathrm{Mn}$ alloys within the impurity band (dashed lines). 
in $\mathrm{Cu}$, second, the solubility increases with increasing the $\mathrm{Mn}$ concentration, and third, the impurity d-band forms in the electronic spectrum of the $\mathrm{Cu}-\mathrm{Mn}$ solid solution, associated with $\mathrm{Mn}$, which is located at $2.05 \ldots 2.15 \mathrm{eV}$ below the Fermi level $E_{\mathrm{F}}$.

Using the results of studies of the electronic structure of pure copper and its optical spectrum [12], we can propose a model of the electronic structure of $\mathrm{Cu}-\mathrm{Mn}$ solid solutions. According to [12], the absorption edge in pure copper at $2.1 \ldots 2.2 \mathrm{eV}$ is associated with transitions of electrons from the peaks of d-band near the $\mathrm{L}_{3}$ Brillouin zone (BZ) to free states of s-p-bands $\mathrm{L}_{2}^{\prime}$ in the vicinity of the Fermi level (FL) $E_{\mathrm{F}}$. Based on the data of experimental studying the optical properties of $\mathrm{Cu}-\mathrm{Mn}$ alloys, it follows that the energy gap between the top of d$\mathrm{Cu}$ bands and Fermi level with addition of $\mathrm{Mn}$ remains unchanged. That is, the position of d-band relative to Fermi level is virtually unchanged in the electronic spectrum of alloys. Intense interband absorption is observed above the absorption edge, which is associated with transitions in the large volume of BZ from 2-nd, 3-rd and 4-th bands into the free states of the sixth band in $\mathrm{L}-\mathrm{W}$ and $\mathrm{D}-\mathrm{X}$ directions of the Brillouin zone [10]. Taking into account that the high-energy peak in the $\sigma(h v)$ curve of copper at $4.7 \mathrm{eV}$ is related to transitions from the sixth to the seventh band, mainly from d-states of $\mathrm{L}_{1}$ to free sp-band levels of $\mathrm{L}_{2}^{\prime}$ [11], one arrives to conclusion that the structure of d-bands located at $4.0 \ldots 4.95 \mathrm{eV}$ lower than the Fermi level is not changed in the alloys and is similar to the d-bands of copper. Thus, the energy bands in the investigated $\mathrm{Cu}-\mathrm{Mn}$ alloys retain the characteristics of the electron spectrum inherent to pure copper.

Assuming by analogy between $\mathrm{Cu}-\mathrm{Fe}$ and $\mathrm{Cu}-\mathrm{Cr}$ alloys $[6,8]$ that the absorption band with a peak at $2 \mathrm{eV}$ in the $\sigma(h v)$ optical spectra is related to electron transitions from the impurity d-subband to free electron states in the vicinity of the Fermi level $\mathrm{E}_{\mathrm{F}}$ and using the obtained data, one can find the distance of the energy center of the impurity band from the Fermi level $E_{d}-E_{\mathrm{F}}$ as well as its half-width $\Delta$. According to the experimental data in $\mathrm{Cu}$ Mn solid solution the value of $E_{d}-E_{\mathrm{F}}$ is about $2.1 \mathrm{eV}$ and almost independent of the Mn concentration, and $\Delta$ increases slightly with increasing the $\mathrm{Mn}$ content in the solution and equals $1.35 \mathrm{eV}(\mathrm{Cu}-2 \% \mathrm{Mn}), 1.4 \mathrm{eV}(\mathrm{Cu}-$ $17.5 \% \mathrm{Mn})$. Based on the obtained $E_{d}-E_{\mathrm{F}}$ density of electronic states, $N(E)$ was calculated for $\mathrm{Cu}-\mathrm{Mn}$ alloys within the impurity band shown in the inset to Fig. 4. Consequently, the resulting electron spectrum of any alloy is a superposition of the spectrum of pure copper with a weight equal to the concentration of $\mathrm{Cu}$ in the alloy, and the density of states of the alloy within the impurity band.

\section{Conclusions}

It is found that a new impurity energy band forms in the electronic spectrum of $\mathrm{Cu}$ with the addition of antiferromagnetic Mn impurities, located approximately
$2.1 \mathrm{eV}$ below the Fermi level $\mathrm{E}_{\mathrm{F}}$, which may split into two energy subbands due to exchange interaction. It is shown that the electron spectrum $N(E)$ of $\mathrm{Cu}-\mathrm{Mn}$ alloys is, in a rough approximation, the superposition of densities of electronic states $N(E)$ of pure copper with a weight equal to its concentration in the alloy, and the density of states within the impurity band.

It has been shown that the optical properties of $\mathrm{Cu}$ $\mathrm{Mn}$ alloys are determined by solvent $(\mathrm{Cu}) \mathrm{d}$-bands and impurity bands $(\mathrm{Mn})$. Due to interband transitions from the solvent d-band to its sp-band, the main absorption band in the $\sigma(h v)$ spectra of $\mathrm{Cu}-\mathrm{Mn}$ alloys is formed. Additional bands appear due to transitions of electrons from the impurity band to the Fermi level $E_{\mathrm{F}}$.

\section{References}

1. Y. Kawazoe, T. Masumoto, K. Suzuki, A. Inoue, Non-equilibrium phase diagrams of ternary amorphous alloys // Condensed Matter, 37, p. 158 (1997).

2. A.K. Ahuja, S. Auluck, S.K. Joshi, Simple model calculations for optical constants of copper // Phys. status solidi, 18, p. 105 (1983).

3. D.P. Norton, D.K. Freenstra, G.W. Ownby, A single, conductive-oxide buffer layer for the development of $\mathrm{Cu}_{3} \mathrm{O}_{7}-\delta$ coated conductors // Appl. Phys. Lett., 79, p. 352 (2001).

4. C. Cantoni, D.K. Christen, E.D. Specht, Deposition and characterization of $\mathrm{Ba}_{2} \mathrm{Cu}_{3} \mathrm{O}_{7}-\delta / \mathrm{LaMnO}_{3} /$ $\mathrm{MgO} / \mathrm{TiN}$ heterostructures on $\mathrm{Cu}$ metal substrates for development of coated conductors // Supercond. Sci. Technol., 17, p. 341 (2004).

5. D.R. Penn, Effects of broadening on BCS theory in the presence of Van Hove singularities // Phys. Rev. Lett. 42, p. 421 (1999).

6. A.E. Doroshenko, V.S. Stashchuk, S.N. Tkachenko, Optical studies of impurity states in $\mathrm{Cu}-\mathrm{Fe}$ alloys // Fizika metallov metalloved., 4, p. 830 (1986).

7. V.S. Stashchuk, Spectroscopy of impurity states of Cu-Co alloys // Visnyk Kiev. Universitety, 4, p. 401 (1997).

8. V.S. Stashchuk, Optical properties of $\mathrm{Cu}-\mathrm{Cr}$ twocomponent systems in intraband transition region // Ukr. Phys. J., 43, p. 282 (1996).

9. H. Fujiwara, Spectroscopic Ellipsometry Principles and Applications. Atrium. Wiley, 2007.

10. L.V. Poperenko, I.A. Shaikevych, V.S. Stashcuk, V.A. Odarych, Diagnostics of Surface with Polarized Light. Kyiv University Publ. House, Kyiv, 2007, p. 130-136 (in Ukrainian).

11. Y. Kakehashi, M. Atiqur, R. Patoary, and T. Tamashiro, Dynamical coherent-potential approximation approach to excitation spectra in $3 \mathrm{~d}$ transition metals // Phys Rev. B, 81, 245133 (2010).

12. V.S. Stashchuk, S.N. Tkachenko, M.N. Yasinska, Spectroscopy studies of electronic properties of copper // Zhurnal priklad. spektroskopii, 44, p. 634 (1996), in Ukrainian. 